\title{
Reforma a la gestión educativa e identidad profesional de los docentes en Argentina: Estudio de un caso
}

\author{
Freytes Frey, Ada Cora*
}

\section{Resumen}

Dentro de la reforma educativa argentina, el $3^{\circ}$ ciclo de la Educación General Básica (EGB) constituye un aspecto central, ya que plantea importantes quiebres con respecto a la estructura anterior. Este ciclo está integrado por los antiguos $7^{\circ}$ grado de la escuela primaria y $1^{\circ}$ y $2^{\circ}$ año de la secundaria, por lo que implica la convivencia de dos culturas profesionales diferentes: la de los maestros y la de los profesores. A esto se suma la reformulación del rol docente que impulsa la reforma. En este trabajo, se analiza la incidencia de estos procesos en la constitución de la identidad profesional de los docentes del $3^{\circ}$ ciclo en la provincia de Buenos Aires. Esto supone una indagación en diversos planos: a) las interpelaciones acerca de la identidad docente presentes en los discursos y lineamientos acerca de la implementación del $3^{\circ}$ ciclo de la EGB en dicha provincia; b) los significados y representaciones identitarias que se van constituyendo en las interacciones cotidianas en las escuelas; c) las maneras en que son recibidas y procesadas estas interpelaciones y representaciones por los docentes del $3^{\circ}$ ciclo, en un trabajo interpretativo que supone también resistencias y reformulaciones. Este planteo supone un contrapunto entre lo macro -abordado a través del análisis de contenido de ciertos discursos públicos- y lo micro -examinado a través de un estudio de casos múltiples en diversas escuelas bonaerenses-.

Palabras clave: Identidad profesional, gestión educativa, docentes, instituciones educativas, educación general básica.

Recibido: 01-10-19. Aceptado: 02-07-23

Licenciada en Sociología. Becaria del Centro de Estudios e Investigaciones Laborales (CEILPIETTE), del Consejo Nacional de Investigaciones Científicas y Técnicas (CONICET). Profesora en la Facultad de Ciencias Sociales de la Universidad del Salvador. Buenos Aires, Argentina. E-mail: afreytes@arnet.com.ar Dirección: Beruti 2526 4ํ Piso - (1425) Buenos Aires, Argentina. Dirección Institucional: CEIL-PIETTE - Saavedra 25 4ํPiso - (1083) Buenos Aires, Argentina. 


\title{
Educational Management Reform and Professional Teacher Identity in Argentina: A Case Study
}

\begin{abstract}
Within Argentine educational reform, the 3rd stage of General Basic Education (EGB) is a central aspect, since it involves important differences with regard to the former educative system structure. This stage is composed by the former primary school 7th grade and secondary school $1 \mathrm{st}$ and 2nd year. Therefore, it involves the daily interaction of two distinct professional cultures: that of primary and secondary school teachers. In addition, the reform policy promotes a redefinition of teachers' roles. The paper analyses the impact of this process on the construction of 3rd stage teachers' professional identity in the Argentine Buenos Aires province. It encompasses different levels of research: a) the interpellations about teaches' identity found in discourses and political measures regarding the 3rd stage implementation; $b$ ) the meanings and representations as to identity constructed during daily interactions in schools; c) the diverse ways these interpellations and representations are received, interpreted and processed by 3rd stage teachers. This approach attempts to explore the macro level through content analysis of public discourses and the micro level through a multiple case study in schools. It also attempts to relate both levels.
\end{abstract}

Key words: Professional identity, educational management, teachers, educational institutions, general basic education (EGB).

\section{Introducción}

Diversos países latinoamericanos han encarado en la última década reformas en su sistema educativo, muchas veces como parte del paquete de medidas impulsadas por los organismos internacionales. La República Argentina no ha sido una excepción en este aspecto: la sanción de la Ley Federal de Educación, en 1993, inauguró un proceso de transformación educativa global, que abarcó, entre otros aspectos, el cambio de la estructura del sistema. En efecto, dicha ley reemplazó la antigua escuela primaria de 7 grados y la secundaria de 5 años por una Educación General Básica (EGB) obligatoria, de 9 años de duración y una Educación Poli- modal, de 3 años. La EGB, a su vez, se dividió en 3 ciclos de 3 años de duración cada uno, con características propias.

En esta política, cobra especial importancia la implementación del $3^{\circ}$ ciclo de la EGB, ya que el mismo plantea el mayor quiebre con el esquema anterior, al unir el antiguo $7^{\circ}$ grado de la escuela primaria y los anteriores $1^{\circ}$ y $2^{\circ}$ año de la secundaria en un nivel único. Por otra parte, en esta instancia se juega también la capacidad del sistema para garantizar en la práctica la obligatoriedad fijada por ley (anteriormente, sólo eran obligatorios 7 años de escolaridad, vale decir, la escuela primaria).

Dos características de la reforma educativa argentina -que obedecen, por otro lado, a los paradigmas de gestión 
hoy dominantes- son la descentralización en la formulación y ejecución de las políticas y la importancia asignada a la autonomía de las escuelas. Con respecto al primer punto, se prevén tres niveles de decisión, escalonados: nacional, provincial e institucional. Los lineamientos generales son consensuados en el Consejo Federal de Cultura y Educación, que reúne al Ministro de Educación de la Nación (MCyE) y a todos los Ministros provinciales del área ${ }^{1}$, pero cada jurisdicción conserva un amplio espectro de decisiones a su cargo en lo que hace a definiciones curriculares, ritmos y esquemas de implementación de la nueva estructura. Asimismo, otra serie de medidas se reservan a los propios establecimientos escolares, que deben confeccionar un Proyecto Educativo Institucional (PEI) particular, abriéndose así nuevas instancias de toma de decisión en la escuela. De esta manera, la descentralización se entronca con el fortalecimiento de la autonomía de las escuelas, considerado un camino para mejorar la gestión educativa, al permitir una mejor adaptación a las diversidades propias de los contextos locales (MCyE, 1998a).

Esto supone, por otra parte, la asignación de nuevas tareas y responsabilidades a directivos, profesores y maestros, lo que se expresa como la necesidad de "reformulación del rol del docente": se promueve un mayor compromiso institucional, el trabajo en equipo y la participa- ción en procesos organizativos y administrativos. Todo esto apuntaría a la "profesionalización", a lograr mediante acciones de capacitación, perfeccionamiento y actualización.

La hipótesis, explorarada en este trabajo, es que los discursos en torno a la "redefinición" del rol docente involucran interpelaciones acerca de lo que "significa ser docente", del "modo de ser docente" adecuado para estos tiempos, descalifican en algunos casos, las prácticas consolidadas, lo cual conlleva un desafío a la identidad profesional de los educadores.

Por otro lado, dado el carácter descentralizado de la reforma, los modelos de implementación del 3ํㅗclo de la EGB varían considerablemente entre las distintas jurisdicciones. En este artículo, nos centraremos en la provincia de Buenos Aires, cuyo sistema educativo, al abarcar el $37 \%$ de los establecimientos y el $40 \%$ de los alumnos del país (vale decir, 4.309.252 alumnos en el 2000), es el más extenso e importante de la Argentina. Además, ha sido una de las jurisdicciones -junto con Córdoba- que ha liderado la reforma educativa, la cual se inició masivamente en su territorio en 1996. Todos estos datos abonan la relevancia del objeto de estudio elegido.

Mencionábamos anteriormente que cada provincia tiene a su cargo una serie de definiciones que hacen a la instrumentación de la reforma en su territorio. Esto ha dado lugar a diversos mode-

1 La República Argentina está compuesta por 23 provincias, a la que se agrega la capital del país, la Ciudad Autónoma de Buenos Aires. Cada una de las provincias y la capital federal constituyen jurisdicciones educativas autónomas. 
los de articulación y puesta en marcha del $3^{\circ}$ ciclo. La provincia de Buenos Aires optó por privilegiar la unidad de la EGB, poniendo al $3^{\circ}$ ciclo bajo la conducción de los antiguos directores de primaria y empleando como docentes tanto a antiguos maestros como a profesores. Estas decisiones apuntan por lo tanto a la integración, en el $3^{\circ}$ ciclo, de dos culturas institucionales y de dos lógicas profesionales diferentes: la de los maestros y la de los profesores. Esto supone la interacción, en las escuelas, de perfiles profesionales con formación, perspectivas educativas y hábitos de trabajo diferenciados.

A partir de lo anterior, la segunda hipótesis que queremos examinar en este artículo es que la convivencia de docentes provenientes de la ex primaria y de la ex secundaria genera conflictos y negociaciones que contribuyen a cuestionar las identidades establecidas de ambos perfiles profesionales.

En suma, en este trabajo buscamos indagar acerca de los cuestionamientos y desafíos que la implementación del $3^{\circ}$ ciclo de la EGB plantea a los docentes estatales en la provincia de Buenos Aires y cómo ellos inciden en el proceso de construcción de su identidad profesional.

Consideramos que la discusión planteada brinda aportes en dos sentidos: por un lado, permite profundizar en las posibilidades de utilización de un concepto teórico de gran nivel de abstracción (el de identidad), como concepto "sensibilizador" que, según la expresión de Blumer (1969), señale direcciones de indagación fructíferas, guiando de esa manera la investigación empírica. En segundo lugar, proporciona información acerca del propio proceso de ejecución de la reforma y de la configuración efectiva que el 3 은 ciclo va adquiriendo en los establecimientos. En efecto, los estudios sobre cambio educativo marcan crecientemente que la implementación de las políticas centralmente diseñadas está mediada por activas respuestas interpretativas de los docentes y demás actores de la institución escolar (Ball, 1989; Beltrán Llavador, 1996). El cambio real no surge nunca de la mera transformación de las reglas, sino que depende del modo en que tal transformación es vivida, incorporada, resistida, entendida por los agentes (Beltrán Llavador, 1996). A lo largo de este trabajo veremos cómo los cuestionamientos que los docentes perciben a su manera de entender la práctica educativa y su identidad profesional, bloquean diversos aspectos que hacen a la puesta en marcha del 3 o ciclo.

El concepto de identidad permite múltiples abordajes, dependiendo del enfoque teórico elegido. De manera que en lo que sigue daremos primero cuenta del recorte conceptual desde el cual examinamos los procesos de transformación identitaria. Posteriormente, exploraremos las interpelaciones acerca de la identidad docente que se desprenden de los discursos y lineamientos acerca de la implementación del 3ํㅗㄷㅇ de la EGB tanto a nivel nacional como en el caso de la provincia de Buenos Aires. Indagaremos luego los significados y representaciones que se van constituyendo en las interacciones cotidianas entre maestros y profesores. Finalmente, analizaremos las consecuencias de estos procesos en la construcción de la identidad docente y en la configuración de estrategias profesio- 
nales que sin duda influyen sobre las características particulares que va adquiriendo el $3^{\circ}$ ciclo en dicha jurisdicción ${ }^{2}$.

\section{El concepto de identidad profesional}

Como ya señalamos, el concepto de identidad es polisémico y pasible de una diversidad de abordajes teóricos. En este apartado no pretendemos realizar una discusión exhaustiva de tales perspectivas, sino delinear sencillamente desde dónde abordamos la identidad profesional.

Una primera nota tiene que ver con el carácter procesual, construido y nunca acabado de la identidad. Esto supone, como lo señalan Hall (1997) y Dubar (1991) un rechazo a una concepción esencialista de la identidad como "naturalmente" dada, a partir de las características "objetivas" de la persona. Por el contrario, la identidad se construye y reconstruye a lo largo de la historia personal en un proceso nunca terminado.

Este proceso remite a un segundo punto clave que es la concepción de esta construcción como una articulación entre el plano biográfico, personal y el plano social o relacional. Esto ya fue señalado desde la psicología por un clásico de los estudios acerca de la constitución de la identidad, Erikson (Citado por Dubar; 1991:108), quien si bien define a esta última como "un sentimiento subjetivo y tónico de una unidad personal y de una continuidad temporal", considera que esta unidad debe construirse a partir de las relaciones dinámicas que el individuo mantiene con los otros que forman parte de su entorno. Estas dos dimensiones de continuidad biográfica y relación con los otros son tomadas por Dubar para caracterizar la identidad social como la articulación de dos procesos heterogéneos: de atribución de identidad por parte de las instituciones y agentes sociales en interacción con el individuo y de incorporación de identidad por parte de los propios individuos. El primero remite a la dimensión relacional-sincrónica de la identidad, el segundo a la dimensión biográfico-diacrónica.

La distinción entre lo biográfico y lo relacional nos parece analíticamente útil, ya que abre un primer camino para pensar la complejidad del concepto. Sin embargo, es precisamente en la articulación de estos dos planos (biográfico y social), mutuamente constitutivos, como lo plantea Hall, donde reside el núcleo del con-

Para responder a nuestros interrogantes, apelamos a una estrategia cualitativa. El estudio de las interpelaciones acerca de la identidad docente que subyacen al discurso oficial sobre la reforma fue abordado a través del análisis lingüístico -que acá no reproducimos- y de contenido de los textos referidos al 3 o ciclo de la revista Zona Educativa, editada por el Ministerio de Cultura y Educación de la nación y a través del análisis de contenido de diversos documentos de los ministerios de Educación nacional y provincial. Para examinar las representaciones e identificaciones de los docentes, realizamos un estudio de casos en 5 escuelas estatales, 3 articuladas y 2 puras, en las que entrevistamos a 5 directoras, 10 profesores, 3 maestras y 3 coordinadores del $3^{\circ}$ ciclo. 
cepto de identidad, como punto de intersección entre ellos. Y esta articulación se realiza en el discurso.

Pero el discurso remite a prácticas particulares de producción simbólica; por lo tanto, a contextos sociales específicos de producción del mismo: a lugares históricos e instituciones concretas, a estrategias discursivas diferenciadas desarrolladas por instituciones y actores sociales. Así, podemos pensar la dimensión relacional de la identidad como un proceso de múltiples interpelaciones ${ }^{3}$ simbólicas por parte de las instituciones y actores con los que el sujeto entra en interacción, interpelaciones a partir de las cuales éste va construyendo su propia identidad "para sí", convirtiéndose en "sujeto capaz de decirse a sí mismo". En este planteo el "para otro" y el "para sí" (expresiones con las que Dubar se refiere a las dimensiones relacional y biográfica de la identidad) están indisolublemente unidos, ya que las producciones simbólicas sociales son el material a partir del cual el individuo construye su "sí mismo" (self), a lo largo de su historia biográfica.

Hall (1997) señala, por otra parte, que las prácticas discursivas se desarrollan en el marco de peculiares juegos de poder. Así, esta noción de poder, subrayada también por Dubar (1991), resulta fundamental para pensar la dimensión relacional de la identidad. En efecto, no todos los actores sociales tienen la misma capacidad de imponer sus propios discursos, sus propias representaciones del mundo. En este punto, podemos introducir el concepto de capital simbólico, desarrollado por Bourdieu $(1985 ; 1987 ; 1994)$. Este autor define al capital simbólico como cualquier propiedad o especie de capital "cuando es percibida por agentes sociales cuyas categorías de percepción son tales que están en condiciones de conocerla (de percibirla) y de reconocerla, de acordarle valor" (1994: 116). Vale decir, se trata de recursos que confieren "reconocimiento", "legitimidad". Ahora bien, para Bourdieu, la eficacia del discurso portador de representaciones sociales depende, en parte, del capital simbólico del que lo emite, esto es, de la autoridad social o reconocimiento que ha adquirido en pugnas simbólicas anteriores. En nuestro planteo, esto nos lleva a poner la mirada en los actores "institucionalizados" del campo educativo, aquellos legitimados para producir un discurso reconocido, con autoridad. Es por eso que en este artículo exploramos las interpelaciones que en torno a la identidad docente se desprenden del discurso oficial acerca del $3^{\circ}$ ciclo producido tanto por el Ministerio de Educación nacional como por el provincial ${ }^{4}$.

No obstante, la producción simbólica no es monopolio de estos actores institucionalizados. El interaccionismo simbólico (Blumer, 1969; Margel, 2000)

3 "La interpelación nombra a una operación discursiva mediante la cual se propone un modelo de identificación a los sujetos sociales. No se trata de un acto intencional sino de un proceso por el cual un sujeto de deseo y de demanda se siente vinculado a un discurso (institución, práctica, etc.) particular" (Duschatzky; 1999). 
pone la mirada en los intercambios cotidianos como lugar de creación, reformulación y transformación de significaciones e identificaciones. Esto nos abre un nuevo camino de indagación, particularmente fructífero para nuestros interrogantes, dado que una de las particularidades del $3^{\circ}$ ciclo es que pone en interacción a docentes con perfiles profesionales muy diferentes.

Ambas perspectivas nos re-envían, por otro lado, a la dimensión biográfica o personal de la construcción identitaria. En Bourdieu (1987:156), la recepción e incorporación de los discursos constructores de identidad dependen, como ya hemos mencionado, del capital simbólico del que lo emite, pero también del grado de pertinencia entre el discurso y los sujetos a los que se dirige, vale decir, de la medida en que el discurso se funda en las propiedades "objetivas" del sujeto. Propiedades que, para él, tienen que ver con el lugar que ocupa en el universo social y con su habitus, como "sistema de esquemas de percepción y de apreciación, como estructuras cognitivas y evaluativas adquiridas a través de la experiencia durable de una posición en el mundo social" (1987: 156). Este concepto de habitus remite, pues, al hecho de que la incorporación por parte del individuo de las interpelaciones simbólicas que pretenden re-significar su identidad depende de transacciones con sus esquemas de interpretación previos, históricamente construidos.

El interaccionismo simbólico, por su parte, rompe en cierta medida con el mecanicismo del concepto de habitus, criticado por algunos autores (entre ellos, Dubar) porque supone cierta introyección pasiva por parte del sujeto de los significados socialmente construidos. Esta corriente, por el contrario, plantea que la incorporación de todo discurso que intenta definir la realidad -en particular, las definiciones identitarias- está mediada por un trabajo interpretativo que supone también resistencia, reformulaciones, construcción de contradiscursos. Desde el punto de vista de la problemática de la construcción identitaria, cobra importancia el trabajo simbólico propio de cada sujeto para unificar las diversas dimensiones de su experiencia social y de sus identificaciones (Margel, 2000).

Ambas perspectivas, nos permitirán pensar tanto la dimensión relacional como la dimensión biográfica de la identidad. Hasta aquí nos hemos referido a la identidad. ¿Qué significa, entonces, identidad profesional? Anteriormente hemos dicho que la identidad se construye y reconstruye a lo largo de la historia personal en un proceso nunca terminado, proceso que es dinamizado a partir de las múltiples relaciones sociales en las que

4 Somos conscientes que éstos no son los únicos actores con amplio reconocimiento en el campo educativo -el cual, por otra parte, está atravesado, como todo campo, por luchas simbólicas por la imposición de una determinada visión de la realidad-. Pero la consideración de otras instituciones -tales como los sindicatos del área o los especialistas en educación- excede las posibilidades de este artículo. 
participa el sujeto. Entre estas relaciones, en la sociedad contemporánea, tienen una importancia fundamental aquellas que se tejen en torno a la propia actividad laboral. Este no es, como queda claro a partir de la discusión que antecede, el único lugar a partir del cual los sujetos constituyen sus referencias identitarias. Ni siquiera postulamos que sea el más importante. Pero, como señala Margel (2000:1), "el trabajo, entendido como relación social... nos remite a un espacio y a una actividad en la cual los trabajadores dan significación a su labor y desde la cual reclaman ser reconocidos. Es precisamente, en este doble juego de construcción de significados propios y de reconocimientos por otros, donde se ubica uno de los nudos problemáticos de la construcción de las identidades profesionales" (2000:1). Este juego es el que queremos explorar en el presente trabajo.

\section{La organización del 3 ciclo: interpelaciones acerca de la identidad profesional de los docentes en el discurso oficial}

Ya al inicio de la reforma educativa, desde el Ministerio de Cultura y Educación de la Nación (1996) se planteó que un punto clave para el éxito de la transformación tenía que ver con el rol y el compromiso que en la misma asumieran los docentes y directivos. Y esto no sólo porque ellos tendrían a su cargo la ejecución de los diseños desarrollados por los técnicos del Ministerio y consensuados en el Consejo Federal de Cultura y Educación, sino porque la descentralización y la autonomía de las escuelas aparecían como notas fundamentales de la política de cambio.
Anteriormente señalamos que cada provincia y la ciudad de Buenos Aires conservan la potestad de decidir en un amplio espectro de temas que hacen a la organización de su sistema educativo. En la misma línea, la reforma plantea un tercer nivel de descentralización, al reservar ciertas medidas y decisiones a los propios establecimientos escolares. En efecto, cada escuela debe confeccionar su Proyecto Educativo Institucional (PEI), bajo la conducción de su director y con la participación del cuerpo docente. Los documentos y artículos que desde el Ministerio nacional impulsan, comentan y difunden la transformación educativa enfatizan el hecho de que la formulación del PEI implica la apertura de nuevas instancias de toma de decisión en la escuela: sobre los objetivos institucionales, las formas de organización, los aspectos curriculares, criterios pedagógicos, metodologías de enseñanza-aprendizaje y sobre el régimen disciplinario, sobre el sistema de evaluación (McyE, 1996-1999).

Así, la descentralización se conecta con la segunda característica enunciada: la autonomía de los establecimientos. Ésta es presentada como una respuesta necesaria a la diversidad cada vez mayor que caracteriza a los alumnos de este ciclo, en términos tanto de su propio proceso de maduración -la transición de la infancia a la adolescencia, caracterizada por cambios físicos, afectivos y cognitivos-, como de su inserción socio-cultural. Tal diversidad requiere estrategias educativas diferenciadas, que sólo pueden surgir de los docentes de cada escuela particular. "El primer paso es reemplazar la lógica de la homogeneidad, que parte del supuesto de que alumnos, docentes y 
contextos son idénticos (construidos desde un modelo ideal), por una lógica de la diversidad, que no sólo reconoce las diferencias individuales y sociales, sino además propone tomar en cuenta estas diferencias para dar a cada alumno o grupo de alumnos los medios necesarios para acceder al currículo. Se trata de buscar las estrategias pedagógicas que den cuenta de los diferentes estilos de aprender según las capacidades y experiencias personales de los alumnos, que deben ser estudiadas y evaluadas en sus respectivos contextos por los docentes. Implica la asunción de responsabilidades por la institución y sus docentes por el resultado de los aprendizajes de los alumnos, y su continuidad en la escuela" (MCyE, 1998b: 21-22).

La última frase de esta cita, con su alusión a la responsabilidad por los resultados es uno de los tantos indicadores presentes en el discurso oficial que muestran desde dónde es pensada esta autonomía: desde los nuevos paradigmas de gestión organizacional, que apuntan a conjugar eficiencia, innovación y flexibilidad. Responsabilidad por los resultados, compromiso institucional, trabajo en equipo, participación en la elaboración del PEI y en los procesos organizativos, así como la capacidad de innovación que permita la adaptación al contexto particular de la escuela, son interpelaciones acerca del "modo de ser docente" adecuado para estos tiempos que se repiten en los documentos y revistas editados por el Ministerio en la década de los ' 90 .

La cita también muestra un mecanismo argumentativo recurrente en el discurso oficial: el mostrar una realidad insatisfactoria y problemática (en el ejemplo, la "lógica de la homogeneidad"), que hay que superar, adoptando nuevas actitudes, esquemas de interpretación y formas de acción. Esta estrategia discursiva es utilizada principalmente para caracterizar la antigua estructura del sistema educativo (presentada como "fragmentada", con "poca articulación" entre materias, "escasa o nula comunicación" entre departamentos y profesores, e incapaz de la flexibilidad), mostrando en contraposición al 3 ciclo como respuesta a sus deficiencias. Pero también es aplicada, en algunos casos, para impulsar el cambio en las prácticas docentes. "La organización del tercer ciclo de la EGB propicia el trabajo de los docentes en distintos tipos de equipos. (...) Hubo experiencias en algunas escuelas medias, organizadas en departamentos de materias afines, pero en general no había un proyecto pedagógico compartido de la escuela, ni sentido de pertenencia del docente, ni tiempo destinado al trabajo en equipo" (MCyE, 1998b: 23).

En resumen, la descentralización y la autonomía institucional, pensadas como medio para mejorar la gestión del sistema y de los establecimientos, requieren por parte de los docentes la asunción de nuevas tareas y responsabilidades y el desarrollo de las actitudes y competencias necesarias para ello. Esto es expresado a través de la demanda de "profesionalización" que el Ministerio, a través de distintas vías, reitera a los educadores. La capacitación aparece como un medio ineludible para adquirir los conocimientos y herramientas pedagógicas acordes con el avance científico y tecnológico de nuestro tiempo y con los requerimientos que plantea la "sociedad del conocimiento". En tal sentido, un aspecto 
fundamental de la reforma ha sido la ampliación y difusión de la oferta de cursos de formación y actualización para los docentes, financiados con recursos públicos y desarrollados por actores públicos y privados del campo educativo (institutos de formación docente, universidades, entidades gremiales y grupos de especialistas). La apelación a la "capacitación continua" es permanente. "Lo que hoy se agrega es la decisión a nivel nacional de llevar adelante acciones comunes sobre temáticas consensuadas, y en cantidad y calidad cada vez más homologable. Es decir, hoy se puede hablar de un verdadero sistema de capacitación docente que, además, formará parte de la nueva carrera profesional docente que, según la Ley Federal, debe ser continua" (MCyE, 1997b: 30).

Otra cuestión que se intenta responder desde los niveles centrales es el tipo de perfil docente que estará a cargo de la enseñanza en el $3^{\circ}$ ciclo. En efecto, como hemos visto, éste abarca cursos que antes estaban a cargo de dos figuras bien diferenciadas: el maestro y el profesor. La decisión de qué perfil privilegiar queda en manos de las provincias. No obstante, desde el Ministerio se hace hincapié en las potencialidades que presenta la integración de ambas clases de docentes -con formaciones diversas- en equipos de trabajo, considerando que cada uno tienen características complementarias: "la experiencia pedagógica de acompañamiento que está más ligada a la figura del maestro primario y el saber disciplinar que tienen los profesores del secundario" (McyE, 1997a: 32-33).

La apelación al trabajo en equipo es, por otro lado, permanente. Éste resulta esencial en diversos ámbitos, propios de la institución o exclusivamente del $3^{\circ}$ ciclo. Tal es el caso de la formulación, ejecución y seguimiento del PEI, la coordinación entre docentes de una misma área -particularmente, en las áreas complejas que reúnen docentes de distintas disciplinas-, o el desarrollo de proyectos interdisciplinarios y de vinculación con la comunidad. Esto último supone, por su parte, cierta flexibilidad en "la organización de los grupos, la utilización de los espacios y la distribución de los tiempos". A la vez, se indican ciertas condiciones necesarias para posibilitar el trabajo conjunto y el compromiso institucional: la concentración de horas en el mismo establecimiento o la designación por cargo y la disponibilidad de tiempos institucionales para reuniones de coordinación, de discusión, de planificación, y de diseño e implementación de proyectos.

Mencionábamos anteriormente ciertas estrategias argumentativas que caracterizan el discurso oficial sobre el 3 응 ciclo en documentos y revistas de difusión. Otra observación que cabe hacer al respecto es que en estos textos el Ministerio se ubica en el lugar del "saber" objetivo. El discurso no es enunciado desde la posición de un actor particular del campo educativo, sino desde la "ciencia" y la "técnica", fundado en procedimientos 
"objetivos" de diagnóstico y formulación de estrategias de intervención ${ }^{5}$. Desde este lugar, los docentes son interpelados a través de un discurso fuertemente normativo, caracterizado por el uso permanente de la modalidad deóntica, que señala cómo "deben ser" sus prácticas profesionales.

Hasta aquí nos hemos referido al Ministerio de Cultura y Educación de la Nación, particularmente durante el anterior gobierno menemista, que impulsó activamente la implementación de la nueva estructura del sistema educativo, consagrada por la Ley Federal de Educación ${ }^{6}$.

En cuanto a la provincia de Buenos Aires, ésta se alineó desde el comienzo con el gobierno nacional, liderando, como hemos visto, la puesta en marcha del $3^{\circ}$ ciclo. Su política con respecto a éste se asentó en una serie de decisiones fundamentales -que aún tienen vigencia-. En primer lugar, el privilegiar la unidad de la EGB, asimilando el 3ㅇcㄷㅇ a la ex escuela primaria y poniéndolo bajo la conducción de los antiguos directores de primaria. En segundo término, una fuerte apuesta por garantizar la obligatoriedad prevista por ley, esto es, la escolaridad universal hasta, por el menos, completar el 9ำ año de la EGB. En tal sentido, no sólo se desplegó una estrategia explícita de retención en el 3 o ciclo, sino que se buscó la reincorporación de niños y jóvenes expulsados del sistema educativo, para que terminaran la educación básica. Como se expresa en la siguiente cita, que reproduce declaraciones de G. Giannettasio, Directora General de Escuelas de la provincia de Buenos Aires durante el gobierno del Dr. Duhalde, esta política de retención aparece ligada a objetivos de contención social y de prevención de la violencia asociada a la pobreza y a la exclusión. "La transformación educativa en la provincia de Buenos Aires tuvo como objeto fundamental lograr una mayor equidad a través de la incorporación de más alumnos al proceso educativo, mejorar la calidad de las estrategias de enseñanza y generar una mayor vinculación de los estudiantes con la cultura del trabajo. (...) Más allá de las denominaciones y de los modos de organización local, lo importante de la transformación es su alto factor de inclusión social, en momentos en donde todos decimos que la exclusión es la causa fundamental del delito, la inseguridad y la injusticia" (Giannettasio, 1999: 28).

Otro eje del diseño del $3^{\circ}$ ciclo propio de la provincia de Buenos Aires fue la organización por áreas. Esta determinación sigue las recomendaciones del Ministerio nacional en el sentido de que la estructura de la EGB 3 debe facilitar la

5 Diversos recursos enunciativos y argumentativos son empleados para ello: la desaparición (casi total) de la primera y segunda persona, y el amplio predominio de la tercera persona-ocultación del locutor que suscribe el discurso a la crítica-; el uso de verbos que tienden a resaltar la objetividad del mensaje y la independencia del mismo con respecto a sus emisores y receptores; la apelación a cifras estadísticas para la caracterización de situaciones.

6 El actual gobierno ha abandonado esta línea de acción, disminuyendo la presión sobre las jurisdicciones para una pronta adopción de la nueva estructura. 
transición entre los dos primeros ciclos de la educación básica y el polimodal. Un porcentaje importante de la deserción escolar, que se concentraba particularmente en los antiguos $1^{\circ}$ y $2^{\circ}$ año del secundario, es adjudicada por los técnicos del Ministerio a la distancia entre las estructuras organizativas de este último y de la ex primaria. El pasar de estar a cargo de una sola maestra, con lo que ello implica de seguimiento y contención, a tener diez o más profesores, en el esquema más bien impersonal del secundario resulta un cambio brusco, difícil de soportar particularmente por los niños y jóvenes de menor capital cultural. Por eso la estructura por áreas resulta coherente con el objetivo de retención ya señalado.

En este punto cabe hacer notar que, en función de las realidades ya existentes en el sistema educativo provincial, el gobierno debió hacer compromisos en la implementación del $3^{\circ}$ ciclo según estas líneas directrices. Uno de ellos estuvo relacionado con las disponibilidades edilicias ya existentes, que motivaron el establecimiento no sólo de EGB completas, que abarcaban los 3 ciclos (las llamadas EGB "puras"), sino de lo que se denominó EGB "articuladas", en las cuales el $7^{\circ}$ año funciona en el antiguo edificio de la primaria, junto con el $1^{\circ}$ y el $2^{\circ}$ ciclo, mientras el $8^{\circ}$ y $9^{\circ}$ permanecen en el edificio de la ex secundaria, aunque bajo la autoridad de los directivos de EGB.

Un segundo compromiso tiene que ver con otra decisión del gobierno provincial: la de garantizar el respeto a los derechos adquiridos por los docentes titulares, manteniendo la cantidad de horas cátedra que tenía antes de la reforma. Esto dio lugar a la implementación de "áreas compartidas" en el caso de áreas como Sociales o Naturales, que unificaban distintas disciplinas.

La puesta en práctica del $3^{\circ}$ ciclo por parte de la provincia de Buenos Aires también implicó la recentralización de decisiones, a nivel de la jurisdicción, que el esquema de la reforma proponía traspasar a las escuelas. Así, mientras la estructura curricular básica para el $3^{\circ}$ ciclo consensuada en el Consejo Federal de Educación, planteaba la existencia de espacios curriculares de opción institucional para permitir el desarrollo de proyectos institucionales propios de la escuela (en particular, proyectos de orientación y tutorías o de vinculación con la comunidad local), éstos fueron eliminados en Buenos Aires. Lo mismo ocurrió con la flexibilidad en la distribución de los tiempos que permitía la propuesta nacional: en el caso de la provincia, los tiempos asignados a cada área están fijados por la autoridad educativa provincial.

El nuevo gobierno provincial ratificó en lo esencial las líneas directrices de la política anterior. Como estrategias de intervención a priorizar enfatizó el impulso de la "profesionalización" docente (que liga la promesa de mejora salarial y de las condiciones de trabajo al cumplimiento de "obligaciones", relacionadas con la capacitación, la asunción de nuevas responsabilidades y la aceptación de instancias de evaluación para los docentes); la descentralización participativa, a través de unidades de planificación distrital; la puesta en marcha de acciones tendientes a favorecer, con participación de la escuela, una mayor integración social de los adolescentes y el desarrollo de una estrategia integral de atención a las pro- 
blemáticas de este grupo etario; $y$, eventualmente, la construcción de nuevos edificios destinados exclusivamente al funcionamiento del $3^{\circ}$ ciclo (Bordón, 2000).

\section{Los docentes ante las interpelaciones del discurso oficial}

\subsection{Una mirada común}

Frente al discurso de los Ministerios nacionales y provinciales, que los interpela desde una racionalidad "profesional", desde un "saber técnico", los directivos y docentes del $3^{\circ}$ ciclo -tanto provenientes de la ex primaria como de la ex secundaria- anteponen su conocimiento de la realidad cotidiana de la práctica educativa, adquirido a partir de la experiencia. Para el Coordinador del $3^{\circ}$ ciclo en una EGC articulada: "Esto fue un trabajo de laboratorio. De mucha gente que tal vez nunca estuvo frente a un aula. Tal vez. Tal vez. No conoce la problemática real. Por eso te bajan información... muchas veces contradictoria, contrapuesta. Hoy dicen una cosa y dentro de un mes viene otro comunicado que se contrapone a lo que vino en junio".

La acusación es recurrente: desde los niveles centrales, generadores de las políticas, se ignoran las situaciones que se viven diariamente en las escuelas, situaciones que aparecen invariablemente caracterizadas por carencias de: Recur$\operatorname{sos}^{7}$, en los alumnos -tanto económicas como en la preparación previa con que llegan al 3 ㅇcㅇ-, en los tiempos disponibles -para reunirse a discutir temas pedagógicos, para concretar el trabajo en equipo y para capacitarse. Las exigencias de nuevos esfuerzos parecen poco realistas e inabarcables. Según la Directora de una EGB articulada: "Nosotros de golpe y porrazo tuvimos... prácticamente, nos duplicaron la cantidad de secciones que teníamos que supervisar, donde en una sección nosotros acá tenemos un maestro y ahora en tercer ciclo teníamos diez, doce profesores por cada sección..." "Lo que pasa que esta situación a los directivos de primaria nos desgasta mucho. Porque hacemos un poco de todo y no nos podemos ocupar de todo a la vez, es mucho... Si nosotros tuviéramos una carga horaria distinta, una jornada completa... por ahí se pueden hacer más cosas. Pero así como estamos, con una carga horaria de cuatro horas y media, es imposible, y menos en esta zona donde hay mucha problemática social".

En este movimiento, los docentes recuperan el derecho a la palabra, que un discurso prescriptivo, enunciado desde "el saber" objetivo y no abierto a la crítica, les niega. Desde las problemáticas que deben enfrentar en su trabajo cotidiano, dirigen hacia el sistema la misma demanda de calidad y eficacia que caracteriza al discurso oficial. Así, critican la improvisación que, a su juicio, ha marcado la puesta en marcha del $3^{\circ}$ ciclo, nacida de la decisión política de incorporar rápidamente 
la nueva estructura, sin tomar en cuenta las condiciones previas necesarias para un cambio efectivo: una adecuada infraestructura edilicia, la capacitación de docentes y directivos.

Esta falta de previsión ha dado lugar, como mencionaba el comentario del coordinador del $3^{\circ}$ ciclo anteriormente citado, a marchas y contramarchas en las directivas en torno, por ejemplo, a las formas de evaluación y acreditación, al régimen de convivencia y entre otras cuestiones, a la capacitación exigida a los docentes. A su vez, la ausencia de las condiciones adecuadas para facilitar la implementación del $3^{\circ}$ ciclo suele ser ligada por los docentes a la insuficiencia de los recursos presupuestarios necesarios para encarar una transformación de esta magnitud. De hecho, en su discurso, muchas veces la reforma educativa aparece relacionada con el ajuste económico.

Los docentes rechazan asimismo el carácter autoritario de la gestión, la falta de consulta tanto a los padres como a los propios docentes. Con esto último, reivindican sus propios saberes y su capacidad de acercar iniciativas y propuestas, a partir de su experiencia profesional. Dice una maestra del $7^{\circ}$ año en una EGB articulada: "Me la paso el año haciendo tareas de compensación... hay chicos que le vino bárbaro, hay chicos que es exactamente lo mismo. Pero no veo un avance en cuanto a que la compensación sirva. Porque de la manera en que la puedo implementar yo, no me sirve. Nosotros solicitamos ante los directivos -y que siga la vía jerárquica correspondiente- la posibilidad de que, por ejemplo, tenemos un grupo para compensar... yo sacrifico una horita a la mañana. En un lugarcito, les doy una hora a ellos solos. Pero no me lo permiten. Porque no tengo responsabilidad civil, porque esas horas no me las van a pagar... Entonces no. Entonces la compensación así no sirve".

Todo esto apunta a resignificar el concepto de calidad, ampliamente utilizado en el discurso oficial, generalmente para condenar las prácticas actuales y legitimar las nuevas propuestas. Como señalamos anteriormente, la medida del "mejoramiento de la calidad educativa", de la "calidad de los aprendizajes" es aplicada a los resultados de la reforma. $Y$ aquí la opinión de los docentes -maestros y profesores- es unánime: los nuevos esquemas de calificación y acreditación implican una disminución del nivel de exigencia y, en la práctica, una desvalorización del esfuerzo y de los logros reales de los alumnos. La sensación es que "no hay premios ni castigos", y que esto redunda en la promoción de los estudiantes sin que éstos hayan adquirido las competencias básicas correspondientes al año aprobado.

Esta situación aparece conectada con la ya mencionada política de retención priorizada por la provincia de Buenos Aires. Como parte de esta política se ha introducido un mecanismo de evaluación diferente: la compensación continua, que

tualizados, falta de equipamiento informático, son observaciones que se repiten en las charlas. 
plantea el desarrollo, a lo largo del año escolar (y durante el horario de clases normal), de actividades extra para los alumnos que no alcanzan diversos objetivos educativos. Luego de finalizado el ciclo lectivo, hay un período de compensación en diciembre y otro en febrero-marzo, que reemplaza a los anteriores exámenes. Este sistema es rechazado por los docentes como ineficaz en términos de los aprendizajes logrados y contraproducente en relación a la formación real acreditada por la escuela. Vale decir, se aumentan los índices de alumnos promovidos, pero a costa de las competencias efectivamente adquiridas por estos alumnos. En tal sentido, la supuesta mejora en los resultados es una ficción. Según un Profesor de Ciencias Sociales en una EGB articulada: "... lo que se ha logrado es descender el nivel. Fíjese que siempre está la oportunidad, la compensación anual, el compensatorio de diciembre, de febrero, de marzo. Después la otra compensación para el que no alcanzó los objetivos y siempre una oportunidad más hasta que en muchos casos -hablando con colegas- ganan por cansancio. 'Muy bien, querido, ¿cómo te llamas? ... has logrado los objetivos, podés retirarte nomás".

Para una maestra del $7^{\circ}$ año de una EGB articulada: "El mismo sistema te implementa una manera de trabajar y no te dice... te dice cómo, pero muy de teoría. Y en la práctica no funciona. No funciona porque no hay tiempo real, porque no hay lugar, porque no dan posibilidad. Si hubieran puesto un docente en cada escuela que se dedique específicamente a compensación y que pueda atender todos los casos particulares, entonces sí ahí se verían logros. Esto es otra cosa que compartimos también con los profesores. (...) Y el sistema te dice: 'Bueno, señorita, usted para hacerlo repetir téngame todas las actas hechas, eh? Porque sino te viene la mamá...' Entonces vos decís, ¿será posible??? (...) Entonces es como que siempre tenés las espaldas descubiertas. Y vos creo que sos la única... la que tiene la última palabra, la que puede decir este chico sabe 0 no sabe. Entonces tenés quien dice: 'Ma sí, que pase a $8^{\circ}$ y se estrelle'. $Y$ tenés las otras locas como yo que digo: 'No, no pasa', ¿te das cuenta?".

En esta última cita advertimos cómo ciertos aspectos de la estrategia de retención en el sistema escolar enfatizada por la provincia son percibidos como una descalificación del docente, como un factor que contribuye a reforzar la pérdida de autoridad (entendida en términos de legitimidad, de reconocimiento) frente al alumno y a los padres que maestros y profesores experimentan en función de transformaciones sociales más amplias, a las que nos referiremos posteriormente. En tal sentido, parece que las prácticas se han invertido: ya no es el alumno que tiene que acreditar sus aprendizajes, sino el docente quien tiene que demostrar que el alumno no ha alcanzado los objetivos estipulados para ese año. $Y$ en algunos casos, esto es explícitamente atribuido a presiones por parte de la provincia para mantener bajos los índices de repitencia. Para una Profesora de Matemática en una EGB articulada: "No es la culpa de la reforma que [los alumnos] vengan con problemas. Obviamente. La culpa es de un todo un sistema... digamos, que hace que muchos alumnos con varias dificulta- 
des pasen de año sin haber completado las pautas mínimas que deberían completar. Con eso, ¿a qué voy? En todas las escuelas hay un porcentaje, ¿sí?... o se manejan porcentajes de repitencia. Obviamente que la escuela no se puede manejar con un porcentaje, porque va a depender de la capacidad de los alumnos... El tema es que, bueno, como hay un porcentaje, se tiene que cumplir ese porcentaje. Hete aquí que puede haber más gente que tenga que repetir el año porque no alcanzó, por dificultades o por lo que sea... dificultades externas al alumno, de su familia, dificultades del alumno, no sé... $x$ causa. Entonces el tema es que hay gente que pasa de año y que no tiene las habilidades. (...) Las escuelas están muy presionadas... los docentes están muy presionados. Te piden un montón de papeles para que vos puedas decir que un alumno no está en condiciones de aprobar... cada vez te ponen más inconvenientes".

Este tipo de observación evidencia las contradicciones percibidas en un discurso que, por un lado, demanda de los educadores autonomía y profesionalidad $y$, por el otro, restringe sus espacios de decisión -aún los tradicionalmente reconocidos-. La misma acusación de incoherencia y falta de seriedad resuena fuerte $y$ unánimemente con respecto a la capacitación, uno de los ejes, como hemos visto, de la política de "profesionalización" docente. Esta es impugnada, en primer término, desde el punto de vista de la calidad y utilidad de la formación impartida. Las críticas son múltiples: repetitividad y falta de interés de las clases destinadas a fundamentación pedagógica, falta de actualización de los contenidos, descone- xión con la práctica en el aula. En el caso de las áreas complejas (Ciencias Naturales y Sociales), se señala que sólo en ciertas ocasiones (y dependiendo de la capacidad del docente) los cursos abordan la problemática fundamental de este nuevo tipo de espacios curriculares: la interdisciplinariedad. La impresión que se obtiene es de una gran heterogeneidad dentro de la oferta de capacitación: dentro de la multiplicidad de cursos, sólo algunos aportan a la formación del docente, tanto en términos de contenidos como -y ésta es la mayor demanda- de estrategias didácticas para "bajar" esos contenidos al aula. Estos casos "exitosos" aparecen ligados, invariablemente, a la calidad del docente a cargo.

En el caso de los maestros, a las consideraciones sobre la utilidad y eficacia de la capacitación, se agrega la indignación por la desprolijidad de parte del gobierno provincial para fijar los requerimientos de formación docente necesarios para asegurar su continuidad en el $3^{\circ}$ ciclo. Es un ejemplo más de la ausencia de información adecuada y de marchas y contramarchas que caracterizó, para los educadores, la implementación de este ciclo. Para una maestra del $7^{\circ}$ año de una EGB articulada: "Comienzo esta bendita historia de la capacitación docente, $3^{\circ}$ ciclo, circuito $\mathrm{C}$, que se comenzó en diciembre del '95... Eso fue realmente un engaño a los docentes, un engaño, una falta de respeto, una falta de ética total. Porque el gobierno de turno nos había dicho que comenzaba una capacitación masiva en el año '95, noviembre-diciembre y continuaba febrero-marzo del ' 96 y teníamos que optar sí o sí por un área... $A$ partir de ahí, nos llega una circular... que 
dice que además de esa capacitación, que era de 4 horas, de 6 a 10 de la noche, teníamos que hacer una capacitación de 180 horas... Entonces empezamos desde el '96 hasta el '98 agarrando cuanto curso venía. (...) Cuando vamos a presentar los papeles, Red Federal, la misma entidad que nos había convocado nos dice: no, esto no sirve. Lo que sirve es lo de la facultad, la Universidad Nacional de La Plata. Usted tiene que hacer un cursito de matemática de 2 años de duración. (...) Pusimos abogado, iniciamos juicio... porque nos veíamos totalmente engañados... todos los docentes de $7^{\circ}$ grado. Como no hubo respuesta y dijimos, ¿qué podemos hacer los sábados de ocho a una durante dos años?, hagamos el curso. No sea cuestión que después... Y lo hemos terminado este año...".

La cuestión de la capacitación es, por otra parte, un primer punto donde encontramos divergencias en la mirada de maestros y profesores. Los primeros, más allá de sus críticas acerca de los modos en que se organizó y efectivizó la oferta de formación, reconocen unánimemente su necesidad de capacitarse, tanto para conducir -en el caso de los directivos- la nueva estructura, como para enseñar los contenidos básicos comunes que establece la reforma. En los profesores, esta necesidad no aparece manifiesta. Sólo en el caso de las áreas complejas, donde los profesores de una determinada disciplina no se consideran formados como para enseñar las demás disciplinas que la componen. No obstante, como veremos más adelante, frente a esto no se reclama nueva capacitación, sino que se señala la inadecuación de la estructura por áreas. La mirada común frente al discurso oficial se bifurca al considerar las perspectivas de los docentes sobre el 3 을. ciclo.

\subsection{Divergencias entre maestros y profesores: apreciaciones sobre el $3 \circ$ ciclo}

\subsubsection{Los maestros ante el $3^{\circ}$ ciclo: posibilidades y desafíos}

En el punto anterior hemos visto que, ante el discurso oficial que impulsa nuevas prácticas y actitudes en los docentes, descalificando -muchas veces en forma implícita- las ya existentes desde el lugar del "saber" técnico y objetivo, los docentes afirman su derecho a opinar y realizar propuestas acerca del cambio educativo, a partir de su experiencia profesional cotidiana. $Y$ es desde esta postura que dirigen duras críticas a la implementación del $3^{\circ}$ ciclo.

Ahora bien, en el caso de los maestros de la ex primaria, tales críticas no implican un rechazo del $3^{\circ}$ ciclo tal cual ha sido delineado en la provincia de Buenos Aires. Por el contrario, se advierte en estos docentes una fuerte apuesta por la nueva estructura, que se expresa en la demanda por asegurar la efectiva unidad de la EGB 3. Señala una Maestra del $7^{\circ}$ año de una EGB articulada: "Entonces ahora, ¿con qué nos encontramos? Nos encontramos con un $3^{\circ}$ ciclo extremadamente conflictivo. Puntualmente en esta escuela yo estoy acá, solita. $Y$ tengo $8^{\circ}$ y $9^{\circ}$ en otra escuela. Son mis alumnos, pero yo no los veo, no puedo conectarme con el profesor, no puedo decirle al profe- 
sor de Matemática: 'mirá, fulano de tal es tal caso, éste fue el seguimiento, ésta fue la respuesta de los padres'. (...) Entonces, la necesidad específicamente de esta escuela es que el $3^{\circ}$ ciclo funcione en un mismo lugar".

Este apoyo tiene, por un lado, un carácter instrumental. En la práctica, los maestros son los que más beneficios han obtenido del cambio de estructura. En primer término, beneficios salariales: sus remuneraciones fueron equiparadas a las de los profesores y ya no cobran por cargo, sino por hora cátedra, lo que representó un interesante aumento. En segundo lugar, ciertas garantías de continuidad: inicialmente, sus cargos eran provisionales, pero se les aseguraba la continuidad por estar en el 30 ciclo. Posteriormente, al finalizar la capacitación en la Universidad han sido titularizados. Una maestra nos mencionó además la posibilidad de tomar dos cargos (mañana y tarde) por dar clase en este ciclo. Por último, dar clase en el $3^{\circ}$ ciclo amplía sus perspectivas profesionales ya que, una vez completada esta capacitación, estarán habilitados para dar clase en $8^{\circ}$ y $9^{\circ}$ año. Esto nos remite a otra de las razones que tienen los maestros para apostar por la unidad del $3^{\circ}$ ciclo: éste representa para ellos una posibilidad de crecimiento y de reconocimiento profesional, un "desafío", manifiestan algunos de ellos.

Por otra parte, se advierte en estos docentes una mayor receptividad a las propuestas pedagógicas, a las perspecti- vas sobre la enseñanza que involucra el discurso oficial sobre la reforma. Nuestra hipótesis es que esto obedece a dos factores. Por un lado, a que tales propuestas y perspectivas son cercanas y se relacionan con su propia experiencia profesional y su modo de entender la docencia. En tal sentido, las interpelaciones acerca del compromiso institucional son fácilmente aceptadas por los maestros que están acostumbrados a trabajar muchas horas en un establecimiento, a involucrarse en distintas actividades propias del mismo -desde actos escolares a diversos proyectos colectivos-, a tener un intercambio activo con sus colegas con los que comparten muchas horas de trabajo. Este hecho, por otro lado, favorece y posibilita el trabajo conjunto y la comunicación entre los docentes. Es así que los maestros invariablemente mencionan que han participado en la elaboración del PEI de la escuela, que han realizado actividades de intercambio y de secuenciación de contenidos con docentes del $1^{\circ}$ y $2^{\circ}$ ciclo, y se muestran al tanto de los proyectos existentes en la institución. Asimismo, su formación general los predispone más al trabajo interdisciplinario ${ }^{8}$ y a aceptar la estructura por áreas, que tanta resistencia genera en algunos profesores. Por último, el énfasis en la contención del adolescente en la EGB ligado a la política de retención del gobierno provincial responde al perfil profesional del maestro, más centrado en el seguimiento y acompañamiento del alumno. allá de la simple superposición de temas pertenecientes a distintas disciplinas. 
El segundo factor tiene que ver con el menor capital simbólico de los docentes primarios en relación con los profesores. La hipótesis que sostenemos es que este menor capital simbólico relativo conlleva un mayor respeto y reconocimiento a los técnicos y especialistas en educación, poseedores, ellos mismos, de una capital simbólico mayor en el campo educativo. Esto refuerza, por lo tanto, la incorporación por parte de los maestros de interpelaciones acerca de su práctica profesional que, por otra parte, se acercan a su "habitus" profesional.

\subsubsection{Los profesores ante el $3^{\circ}$ ciclo: desvalorización y amenaza}

La perspectiva de los profesores ante el $3^{\circ}$ ciclo tal cual ha sido diseñado por la provincia de Buenos Aires es totalmente opuesta. Mientras que los maestros critican las falencias en la implementación del mismo, pero apuestan a la continuidad de la transformación en marcha, los profesores culpan específicamente a la estructura actual de la pérdida del sentido fundamental de la institución escolar: la educación, la formación de los alumnos. Señala un docente de plástica en una EGB y además docente en el Polimodal de una escuela técnica, de profesión arquitecto: "Yo soy docente, no soy contenedor. No soy guardián, ni de una guardería. Sé que hay inspectoras que piden que hay que contenerlos, porque la calle está dura, entonces la escuela es un medio de contención. Pero creo que estamos equivocados. Es decir, habrá que corregir parte de la sociedad... Pero los objetivos de la escuela es instrumentar gente capaz para asumir cosas...".

Un primer punto a tener en cuenta para comprender esta perspectiva es que, en tanto para los docentes provenientes de la ex escuela primaria el $3^{\circ}$ ciclo representa una mejora salarial, nuevas perspectivas de carrera, cierto desafío profesional, para los que vienen de la ex secundaria, éste significa, por el contrario, una pérdida de status, una degradación que afecta su propia identidad profesional. Según el Coordinador del $3^{\circ}$ ciclo de una EGB articulada: "Fue traumático sobre todo para los profesores. Salir de la escuela media -pensábamos en ese momento- para volver a la escuela primaria. No tenía sentido, no estábamos preparados para la tarea del docente de escuela primaria. Hubo muchos docentes que se resistieron. Yo fui uno de ellos, y me sigo resistiendo, porque me parece que este cambio no dio los resultados que las autoridades esperaban. Visto en tres años de aplicación".

Nuevamente, surgen aquí consideraciones de orden instrumental. Para los profesores, la puesta en marcha del $3^{\circ} \mathrm{ci}$ clo no sólo no significó ninguna mejora salarial $^{9}$, sino que en muchos casos afectó la concentración de sus horas en pocos establecimientos o la coordinación de sus

Con excepción del cobro del incentivo docente que, de todas maneras, abarcó a todos los docentes y cuyo cobro ha estado signado, desde su creación, por recurrentes inconvenientes y demoras. 
horarios entre distintas escuelas. En este sentido, muchas de las propuestas de transformación de las prácticas docentes -el trabajo en equipo, el compromiso institucional, la participación en la formulación del PEI, la elaboración de proyectos interdisciplinarios- suponen condiciones de trabajo que son ajenas a la realidad de los profesores, que distribuyen sus horas de trabajo en diferentes instituciones y no cuentan, por lo tanto, con tiempo disponible para reuniones de planificación, de coordinación entre diversas disciplinas o de diseño de proyectos. Esto es reconocido por los responsables del sistema educativo. De hecho, desde la Nación primero y desde la provincia posteriormente se ha impulsado una política de concentración de horas de los profesores en pocos establecimientos. Sin embargo, al momento de nuestro trabajo de campo, tales iniciativas no habían llegado a plasmarse en hechos concretos.

Por lo tanto, la percepción de los docentes provenientes de la ex secundaria -muchos de los cuales, por otra parte, continúan dando clase en el polimodal-, es que los que impulsan este diseño del $3^{\circ}$ ciclo hacen caso omiso de las condiciones reales de desempeño de sus tareas. Esta distancia entre las interpelaciones acerca del "modo de ser docente" adecuado para estos tiempos y este ciclo y las prácticas habituales de los profesores se extiende a otras cuestiones. Las exigencia de trabajo en equipo choca con la tradición establecida, fuertemente individualista. Para una Profesora de Matemática: "El trabajo docente es muy individualista. Y cada uno tiene su teoría con res- pecto a cómo da clase, con respecto a cómo querés que estén los alumnos adentro, qué pautas les mantenés de conducta, qué cosas hacés vos de ejemplo... Entonces como hay tanta diferencia es también medio difícil que vos después cuando te tengas que poner a charlar sobre un área también coincidas. $O$ sea, hay un bloque, o un tronco que es relativamente fundamental, que uno no se mueve porque son los contenidos. Pero después dentro de la misma escuela, si vos agarrás tenés personas totalmente distintas dando clase de formas totalmente distintas. $Y$ es medio difícil. También depende mucho de la apertura de la persona y si realmente quiere hacer algo en equipo para trabajar bien o si te dice: sí, sí, sí y después detrás de la puerta hace lo que quiere".

En la misma línea operan el impulso de proyectos interdisciplinarios o la propia estructura en áreas, que plantea, en algunos casos, la articulación de disciplinas diferentes (en Ciencias Sociales, en Ciencias Naturales y, más raramente, en Educación Artística). Esto último es particularmente criticado y resistido por los profesores, en tanto pone en cuestión su propia identidad profesional, fuertemente basada en el dominio de una disciplina particular. Pongamos un ejemplo: para un profesor de Física, pretender que un profesor de Biología enseñe Física (en el área de Ciencias Naturales) sin una formación específica -0, a lo sumo, con una capacitación "ad hoc"- implica una desvalorización de sus propias competencias profesionales. A su vez, se siente insuficientemente preparado para enseñar 
Biología ${ }^{10}$. Desde esta perspectiva, entonces, este cambio atenta contra la calidad de la educación brindada.

Asistimos, nuevamente, a una resignificación del discurso de la calidad y de la profesionalidad, tan repetido desde la conducción del sistema educativo. Tal demanda es dirigida contra ellos mismos. Las autoridades educativas reclaman la "profesionalización" de los docentes. Pero, contradictoriamente, emplean como profesores gente no idónea para el cargo: porque no están formadas para dar determinados temas (es el caso de las áreas complejas), porque ni siquiera tienen título docente (se mencionan casos de estudiantes universitarios o terciarios no recibidos o de técnicos que sólo tienen la escuela media terminada) o porque, ante la desaparición de determinadas asignaturas se ha "reconvertido" a sus titulares, en formas verdaderamente curiosas ${ }^{11}$.

En resumen, muchas de las transformaciones que involucra el 3 o ciclo tal como se ha implementado en la provincia de Buenos Aires ponen en cuestión la concepción misma del trabajo docente que sostienen los profesores. Y es a partir de este cuestionamiento a la propia identidad profesional y de la percepción de una pérdida de status que estos docentes rechazan tales cambios. A diferencia de los maestros, su reclamo es abandonar esta línea de reforma y buscar otras alternativas, señalando además la falta de preparación de los docentes y directivos de la ex primaria para educar a los adolescentes. Esta última observación nos introduce en el próximo punto, donde examinaremos los desafíos a la identidad profesional de maestros y profesores que supone la convivencia de ambos perfiles en el $3^{\circ}$ ciclo.

\section{La interacción en la escuela de maestros y profesores: la mirada del otro}

Al discutir el concepto de identidad profesional, hemos visto que las interacciones cotidianas en el ámbito de trabajo resultan fundamentales para la creación, reformulación y transformación de representaciones identitarias. A su vez, a partir de lo discutido hasta el momento, se hace evidente la divergencia en los modos de entender la práctica docente de maestros

10 Una consecuencia ligada a esta percepción es que muchas veces estas áreas complejas son una ficción. En el caso de que el área esté a cargo de varios profesores (como ocurre en muchas escuelas articuladas), la coordinación entre los mismos es casi nula -por ausencia de tiempos institucionales- y se reduce generalmente a lograr cierto consenso con respecto a las notas finales. Cuando el área está a cargo de un único profesor, éste tiende a priorizar, lógicamente, la disciplina en la cual se formó. Aunque en estos casos la articulación de contenidos es más viable.

11 Como el caso de una de nuestras entrevistadas, profesora de Francés, que actualmente está dando Lengua, con gran insatisfacción personal y problemas con sus alumnos. O un arquitecto, profesor en una escuela técnica con especialidad en Construcciones, que por pérdida de horas titulares fue enviado a dar Educación Plástica en $8^{\circ}$ grado, en una EGB pura. 
y profesores. En tal sentido, la "mirada del otro" (de los profesores para los maestros, y viceversa) contiene también interpelaciones y desafíos a las propias concepciones y formas de percibirse a uno mismo. Esto es lo que vamos a examinar en los dos apartados que siguen.

\subsection{La mirada de los profesores hacia los maestros}

A esta altura resulta evidente la desvalorización de la ex escuela primaria por parte de los profesores. Si el $3^{\circ}$ ciclo conlleva cierta degradación o pérdida de status para ellos, es porque pasan a pertenecer a la EGB, aunque esta pertenencia resulte sólo formal y sea en la práctica resistida por los profesores. Como señalamos anteriormente, los profesores desconfían acerca de las posibilidades de maestros y directivos de EGB de formar adolescentes. De hecho, una expresión recurrente es que el $3^{\circ}$ ciclo, al mantener a los alumnos "en la escuela primaria" impide su maduración: continúan siendo "niños" en su comportamiento, caracterizado a menudo por la indisciplina, la dificultad de atención, la falta de respeto hacia el profesor.

Esta situación tiene que ver con ciertas características percibidas en la ex escuela primaria. Por un lado, la permisividad, la falta de orden y disciplina, relacionada con la concepción de la institución educativa como ámbito de contención. En función de esta noción, las exigencias desde el punto de vista de la comprensión y el aprendizaje son menores -o, inclusive, mínimas, con lo cual se desvirtúa la verdadera función de la escuela-.
Otra crítica frecuente versa sobre la excesiva "burocratización" de la EGB -con su correlato de "papeles que llenar"-, así como la abundancia de "reuniones", que distraen al docente de lo fundamental de su trabajo: la enseñanza. Nuevamente se advierte aquí el modelo individualista de práctica profesional que motiva esta visión, basado en el manejo experto y transmisión de ciertos saberes disciplinares.

No obstante, la desvalorización de la EGB no se manifiesta principalmente en el discurso de los profesores, sino en sus acciones. Ellos se excluyen sistemáticamente de las actividades conjuntas que se realizan en la escuela, más allá del desarrollo de sus clases. Esto se advierte claramente al examinar ciertos procesos como la elaboración del PEI. En el caso de las escuelas articuladas, los docentes provenientes de media no sólo no participan en la confección del mismo, sino que lo desconocen. En el caso de las EGB puras la intervención en la formulación es nula o la estrictamente indispensable (acuerdos acerca de la secuenciación de contenidos, o bien la asistencia obligatoria a las Jornadas de Capacitación estipuladas por la provincia).

Estas Jornadas de Capacitación son también una muestra del desinterés de los profesores por considerar y discutir sus práctica pedagógicas con sus colegas provenientes de la ex primaria. Dichas Jornadas constituyen una variante en las estrategias de formación, introducida en el 2000 por la nueva conducción educativa de la provincia, como una forma de acercar la formación a la institución escolar y promover la reflexión sobre el desempeño de la actividad docente. Consisten en talleres de reflexión, con mate- 
riales específicos que proponen las temáticas a ser analizadas y guían el tratamiento de las mismas. Ahora bien, en el caso de los profesores, su pertenencia a varios establecimientos, incluso algunos de nivel medio, hace que, en ocasiones, tengan la facultad de elegir aquel donde realizar la capacitación. Cuando esto ocurre, suelen optar generalmente por alguna escuela media o por una EGB articulada, donde maestros y profesores sólo ocasionalmente comparten estas reuniones.

Los ejemplos pueden multiplicarse. Lo que queda claro es que los educadores provenientes de la ex secundaria no consideran particularmente enriquecedor el intercambio con los maestros, proyectando con esta actitud una mirada de cierto menosprecio hacia estos últimos. En lo que sigue veremos como es esto percibido por los maestros y cuál es su repuesta.

\subsection{La mirada de los maestros hacia los profesores}

La visión desvalorizadora que venimos de describir es claramente percibida por maestros y directivos de primaria. Estos últimos, al enumerar las dificultades inherentes a la puesta en marcha del $3^{\circ}$ ciclo, mencionan la resistencia de los profesores a ser observados en sus clases y evaluados por ellos. Y, acto seguido, expresan sus propios límites para realizar esta evaluación, relacionados con la carencia de ciertos saberes conceptuales. Al respecto expresa la Directora de una EGB articulada: “...porque a nosotros nos exigieron la capacitación a los directivos, del tercer ciclo y, bueno, la realizamos pero no... no somos... uno trata de capa- citarse en forma particular, pero de los saberes propios de cada una de las áreas no tiene el conocimiento. Yo, por ejemplo, si tengo que ir a supervisar Inglés, puedo supervisar a nivel pedagógico, si la clase se desarrolla como corresponde, pero no en conocimientos propios de la materia".

A su vez, los maestros dan cuenta de las reticencias de los profesores a aceptar sus puntos de vista y sugerencias con respecto a las prácticas pedagógicas; su desinterés ante la transmisión del conocimiento personal acerca de los alumnos, adquirido a lo largo del curso anterior -un hábito, al parecer, entre los docentes de la escuela primaria-. Esto se evidencia en la ausencia de los profesores en los pocos espacios de intercambio existentes -las Jornadas de Capacitación mencionadas-, justificada, sin embargo, por sus condiciones de trabajo. Según una maestra del $7^{\circ}$ año, en una EGB articulada: "Hace dos años se hizo una selección de contenidos, o sea, hicimos la currícula de la escuela. (...) Y después hicimos los finales... los contenidos finales, o sea, las expectativas de logro, lo que dice que vas a promoverlo o no al alumno. Hicimos así: cada docente hizo el de su año, después todas las docentes de $1^{\circ} \mathrm{Ci}$ clo... todas las docentes de $2^{\circ} \ldots$ y siempre quedo yo sola del 3 o ciclo... porque nunca me junto con los profesores..." (subrayado nuestro). Para la Directora de una EGB articulada: "... lo que sucede más que nada con los profesores es que no... no se resignan a pertenecer a primaria, y cuando uno hace una Jornada de Capacitación le trae la constancia de que estuvo en una escuela media haciendo la capacitación. Tienen esa resistencia". 
Esta mirada desvalorizadora es rechazada por los maestros. Desde su propia identidad profesional, desde su modo de entender la práctica docente dirigen su propio examen crítico sobre sus colegas. En esta instancia, el discurso oficial de la reforma -más cercano, como hemos visto, al modelo de la ex primaria- les sirve de soporte legitimador.

Una primera crítica se refiere a la rigidez percibida en los profesores, que insisten en una rutina específica de temas y formas de tratamiento de los mismos, sin tomar en cuenta las características particulares del curso en el que enseñan. Esto aparece ligado a la ausencia de innovación en sus prácticas didácticas. La adopción de nuevos esquemas de planificación y organización de la actividad, como el trabajo por proyectos, encuentra grandes obstáculos. En tal sentido, el contacto con la primaria es presentado como enriquecedor. Según la Directora de una EGB pura: "A lo largo de los años de funcionamiento del $3^{\circ}$ ciclo, las propuestas pedagógicas de los profesores incorporados al $3^{\circ}$ ciclo han ido evolucionando paulatinamente. Inicialmente tenían una propuesta homogénea, suponiendo que el grupo tenía ya adquiridas ciertas conductas, ciertos hábitos de trabajo, ciertas normas de convivencia. Ahora presentan propuestas más adaptadas a las necesidades y a las características de los grupos. Lo actitudinal, lo procedimental y lo social -las relaciones sociales- han sido revalorados por los profesores como contenidos a trabajar. Y no sólo centrarse en lo conceptual, en el conocimiento. Esto ha llevado su tiempo, pero se ve".

En la cita anterior aparece nuevamente la preeminencia de lo conceptual, que deja afuera otros aspectos de la formación. En la misma línea, se menciona la ausencia de un abordaje integral y personalizado del alumno, que tenga en cuenta aspectos emocionales y socioeconómicos.

Asimismo, se enfatizan las dificultades de los profesores para el trabajo en equipo, atribuida en parte a sus condiciones de trabajo (el docente "taxi"), pero también a un estilo individualista en el ejercicio de la enseñanza. En tal sentido, en el marco del 3 ํ ciclo, cobran relevancia los problemas de coordinación y articulación con otros colegas, por ejemplo, para la construcción conjunta de las áreas complejas 0 , como se mencionaba en una cita anterior, para la secuenciación y adaptación de los contenidos básicos comunes -definidos por ciclo- según las características particulares de la escuela.

Por último, se señala la falta de compromiso institucional de los docentes provenientes de media. La múltiple pertenencia institucional y la concatenación de horarios entre distintos establecimientos muchas veces resulta una excusa conveniente para no involucrarse en los proyectos institucionales o en los espacios grupales de reflexión. Al respecto dice una maestra del $7^{\circ}$ año: "Porque el profesor, ¿viste?, es muy mezquino. O sea, no es que diga: 'sí, voy'. No. Hoy tengo que venir acá y me corresponden dos horas, y a las dos horas y cinco se está yendo. Y vos te quedás, ¿viste?, el amor a la escuela... (risa) Ese tipo de cosas".

Como se advierte en la última cita, esta visión negativa del "otro" es el trasfondo contra el cual se afirma la propia identidad positiva, amenazada a su vez por el discurso y las actitudes desvalorizadoras 
de los profesores. Así, los maestros enfatizan su propio compromiso con la escuela -evidenciado en la participación en la elaboración del PEI y en su conocimiento acerca de los proyectos pedagógicos en marcha- $y$ con los alumnos -a los que conocen en profundidad, a partir de un seguimiento personalizado-. Al mismo tiempo, subrayan la importancia de las competencias específicas que les brinda su formación -fundamentalmente, recursos pedagógicos y didácticos- para generar respuestas adecuadas a los contextos sociales cada vez más problemáticos en que se desenvuelve la institución escolar.

La consecuencia más relevante y a la vez negativa de este desencuentro de miradas es la falta de comunicación y coordinación real entre las dos figuras a cargo del 3 ciclo: maestros y profesores. En tal sentido -y especialmente en las EGB articuladas- la unidad del 3 o ciclo es una ficción. En las EGB puras la convivencia es inevitable, pero las potencialidades de la misma resultan bloqueadas por la desconfianza y la incomprensión mutuas. Y, por otra parte, en este caso son frecuentes los relatos de "huida de la EGB" por parte de los profesores, que prefieren dar clase ya sea en el polimodal o en EGB articuladas. Es así que en estas escuelas se concentran los docentes con menor puntaje, presentando además una alta rotación que atenta contra la continuidad de los proyectos pedagógicos. A la larga, todo apunta en la misma dirección, a generar grandes dificultades para responder al mayor desafío que se desprende de los relatos tanto de maestros como de profesores: ¿cómo brindar una educación efectiva y significativa a los adoles- centes que hoy pueblan las escuelas públicas?

\section{Un desafío común: ¿cómo educar a los adolescentes en la actualidad?}

Esta es, efectivamente, una preocupación recurrente que atraviesa el discurso de los docentes entrevistados. Un interrogante que obedece, en primer término, a una constatación: la degradación del nivel socio-económico de la población que asiste a la escuela pública, producto, por una parte, de la repercusión de fenómenos tales como la desocupación y el deterioro de los salarios $y$, por otra parte, de la concentración en ésta de los sectores más castigados por dichos fenómenos, lo cual profundiza la diferenciación entre establecimientos públicos y privados. Para una Profesora de Matemática: "Ahora se está abriendo mucha brecha entre lo que es una escuela privada y una escuela pública. Ahora ya hay mucha diferencia socioeconómica entre la gente que manda el hijo a la escuela privada y la gente que manda al hijo a la escuela pública".

Esta situación enfrenta a los docentes con nuevos desafíos. En primer lugar, la falta de recursos pedagógicos. Los educadores deben agudizar su imaginación para suplir la falta de libros de texto y de otros implementos escolares -a la cual se suma la ausencia de equipamiento adecuado en la escuela-. En segundo término, la aparición -o agravamiento- de problemáticas y circunstancias que se alejan de la "imagen tradicional" del alumno -y especialmente, del alumno de escuela media-: embarazos precoces, inasistencias prolongadas con 
motivo de trabajos temporarios o responsabilidades familiares de los jóvenes. A esto se agrega, en muchos casos, la carencia de un ambiente familiar que acompañe al adolescente en su educación: padres con escaso capital cultural, con largas jornadas de trabajo y serias dificultades económicas.

Sin embargo, hay que señalar que esta última situación no está ligada únicamente a los problemas socio-económicos. La desintegración de los modelos familiares tradicionales -como las demás transformaciones sociales propias de este fin de siglo- repercute también en la institución educativa. Es así que los docentes expresan la impresión generalizada de "ausencia de los padres", que se desentienden del desempeño escolar de sus hijos.

Esto tiene su correlato en la falta de interés de los alumnos por los contenidos y enseñanzas transmitidos en la escuela. La motivación que moviliza el aprendizaje parece cada vez más difícil de lograr. A su vez, los educadores se encuentran con estudiantes que responden cada vez menos a sus expectativas en cuanto al manejo de ciertas competencias básicas -que se suponen adquiridas en etapas anteriores de la EGB-y a la internacionalización de ciertos códigos de conducta y convivencia. Según un Profesor de Ciencias Sociales en una EGB articulada: "Lo que yo le decía hoy, no leen, no saben expresarse. Entonces, no hay ningún chico que quiera hablar. (...) Pero en octavo año se me hace difícil. Se me hace difícil la falta de comprensión. Yo trabajo mucho con diarios por ejemplo, porque no puedo exigir libro -usted me preguntó la situación socioeconómica, un $92 \%$ clase baja-. Yo traigo recortes de diarios sobre temas que están vinculados con la planificación y con el programa que corresponde para octavo o noveno año. No comprenden el diario, lo que dice el diario no lo entienden, puede haber un gráfico o un dibujo no saben interpretarlo. Lo mismo sucede con un mapa. Se da cuenta entonces, es grave".

Frente a este panorama, la sensación es de perplejidad, de falta de respuestas. Sensación que es más aguda en los profesores quienes, por la ampliación de la obligatoriedad, se encuentran en las aulas con alumnos que anteriormente eran expulsados del sistema. La política de retención fuertemente impulsada por el gobierno provincial los pone frente al desafío de educar a estos adolescentes, tarea ante la cual muchas veces sienten que no tienen las herramientas adecuadas. Los maestros cuentan con un manejo más amplio de alternativas pedagógicas y didácticas. Pero también ellos aparecen interpelados por estos "sujetos del aprendizaje" que resultan cada vez más extraños y complejos.

De esta manera, aparece un nuevo elemento desestructurante de las identidades docentes establecidas, que ya no tiene que ver con la reforma educativa, sino con cambios sociales "estructurales": en la economía, en los modelos familiares, en la cultura juvenil. Estas transformaciones ponen en cuestión el núcleo de la identidad profesional de los docentes: sus propios modos de concebir la práctica de enseñanza. El desafío fundamental que maestros y profesores enfrentan hoy, por lo tanto, pasa por idear y desarrollar estrategias efectivas para lo- 
grar un aprendizaje significativo por parte de estos alumnos.

\section{A modo de conclusión}

Planteábamos inicialmente que todo proceso de construcción de identidad opera en dos planos: el biográfico, personal y el social o relacional. Por otra parte, esta distinción es analítica ya que la identidad se constituye en el punto de intersección entre estos dos planos. Veamos como esto se advierte en los análisis que hemos realizado.

En primer término, abordamos la dimensión relacional examinando el discurso oficial acerca de la reforma, el cual involucraba múltiples interpelaciones acerca del "modo de ser docente". Tales interpelaciones eran emitidas desde el lugar del "saber", negando legitimidad a otras voces. Al analizar la recepción de este discurso por parte de los docentes advertimos que esta negación de la palabra era rechazada desde la propia experiencia cotidiana de trabajo y que desde este lugar se reclamaba el reconocimiento tanto de los saberes y competencias de los docentes como de su derecho a criticar y a realizar propuestas para mejorar el sistema educativo y las prácticas docentes; a participar, en suma, en la definición de políticas que afectan su trabajo cotidiano y sus perspectivas de futuro. Identificamos asimismo el trabajo interpretativo de resignificación del discurso dominante y de construcción de contradiscursos que postula el interaccionismo simbólico.

Esta indagación nos permitió, por otra parte, reconocer la articulación entre la dimensión relacional y la dimensión biográfica. En efecto, las interpelaciones identitarias y las representaciones que median la interpretación de la realidad son recibidas y resignificadas por los sujetos a partir de su propia trayectoria histórica, de su habitus históricamente formado. Esto se advierte con claridad al analizar la postura ante el $3^{\circ}$ ciclo de maestros y profesores. Las divergencias entre ambos son fácilmente entendibles en función de su propia identidad profesional y de los desafíos que el nuevo sistema representa para su forma de entender la práctica docente y para sus intereses particulares.

Al examinar la mirada recíproca entre maestros y profesores, pudimos discernir con claridad estas dos formas de entender la práctica docente. En la interacción cotidiana en el 3 o ciclo, cada una de ellas representa un desafío para la otra, en tanto pone en acto distintos cuestionamientos a las formas establecidas de desempeño profesional. En este punto, se advierten, por otra parte, las diferencias de capital simbólico: los maestros sienten sobre sí con fuerza el rechazo de los profesores, y reaccionan defensivamente a su mirada, afirmando, no obstante, positivamente la propia identidad, sobre el trasfondo de la crítica al "otro" y apoyándose, en ocasiones, sobre el discurso oficial.

Este potencial cuestionador de la interacción de maestros y profesores puede, a nuestro juicio, ser altamente productivo para enriquecer prácticas profesionales que, como hemos visto en el punto 5 de este trabajo, resultan inadecuadas para asegurar una formación satisfactoria a los adolescentes que asisten al $3^{\circ}$ ciclo. Esta posibilidad se encuentra 
hoy, sin embargo, bloqueada. En parte por la desconfianza y la incomprensión mutuas. Pero también porque, desde el sistema educativo no se han facilitado las condiciones para hacer efectiva esta interacción. Como hemos señalado anteriormente, el $3^{\circ}$ ciclo -con todos los aspectos que involucra: integración con el resto de la EGB y articulación con el polimodal, construcción seria de las áreas complejas, discusión y reflexión acerca de los esquemas de trabajo establecidos, formulación de proyectos interdisciplinarios- es hoy una ficción imposible de realizar si no se consideran las condiciones reales en que se desarrolla la práctica educativa de maestros y profesores.

Que la interacción entre ambos perfiles profesionales se concrete puede resultar de fundamental importancia para hacer frente al desafío más importante y vital que no sólo los docentes, sino la sociedad en su conjunto debe hoy atender: cómo brindar una educación efectiva y significativa que permita por lo menos aliviar el ciclo de reproducción de la pobreza y la marginalidad que hoy se advierte en las escuelas públicas bonaerenses.

\section{Bibliografía Citada}

\section{Ball, Stephen J. (1989), La micropolítica de la} escuela. Hacia una teoría de la organización escolar. España, Paidós.

Beltrán Llavador, Francisco (1996), Las instituciones en el cruce de caminos, en Frigerio, Graciela; Pozzi, Margarita; Giannoni, Mario (comps.): Políticas, instituciones $y$ actores en educación. Argentina, Ediciones Novedades Educativas.
Blumer, Herbert (1969), Symbolic Interactionism. Perspective and Method. Estados Unidos, Prentice-Hall Inc., Englewood Cliffs.

Bordon, José O. (2000), Informe sobre el estado de la educación bonaerense 1999-2000. Http://abc.gov.ar/ComunidadyCultura/comunicacion/prensa/ bordon/discbordon.htm. Consulta del 10-5-2001.

Bourdieu, Pierre (1985), ¿Qué significa hablar? Economía de los intercambios lingüísticos. España, Ediciones Akal.

Bourdieu, Pierre (1987), Espace social et pouvoir symbolique. Choses dites. Francia, Les Éditions de Minuit.

Bourdieu, Pierre (1994), Esprits d'État. Genèse et structure du champ bureaucratique. Raisons pratiques. Sur la théorie de l'action. Francia, Éditions du Seuil.

Dubar, Claude (1991), La socialisation, construction des identités sociales et professionelles. Francia, Armand Colin.

Duschatzky, Silvia (1999), La Escuela como Frontera. Paidos. Buenos Aires.

Giannettasio, Graciela (1999), Provincia de Buenos Aires. Inclusión social y equidad. Zona Educativa. Año 4, № 32, Argentina, Ministerio de Cultura y Educación, p. 28.

Hall, Stuart (1997), "Who needs identity?". Hall, Stuart y Du Gay, Paul: Questions of cultural identity. Inglaterra, Sage.

Margel, Geyser (2000), "La reconfiguración de las identidades profesionales ante los cambios socio-técnicos: la difícil tarea de construir una nueva "definición de sí". Ponencia presentada en el 3 o Congreso Latinoamericano de Sociología del Trabajo, Buenos Aires, Mayo. 
Ministerio de Cultura y Educación (McyE), Dirección General de Investigación y Desarrollo (1996). Marco para la organización del Tercer Ciclo de la Educación General Básica. CONSUDEC. Año XXXIII, № 792, Argentina, Consejo Superior de Educación Católica, ps. 32-37.

Ministerio de Cultura y Educación (MCyE) (1996-1999), Sección 3er. Ciclo de la Revista Zona Educativa No. 8 a 32. MCE. Buenos Aires.

Ministerio de Cultura y Educación (MCyE) (1997ª), EGB3: Lo más nuevo de la nueva educación. Revista Zona Educativa No. 12. Año 2. MCE. Buenos Aires.

Ministerio de Cultura y Educación (MCyE) (1997b), Tiempo de Profesionaliza- ción. Revista Zona Educativa No. 17. año 2 MCE. Buenos Aires.

Ministerio de Cultura y Educación (McyE) (1998a), La Educación Argentina en la Sociedad del Conocimiento - Informe Anual para la 29ำ Reunión de la Conferencia General de la UNESCO.

http://www.zona.mcye.gov.ar/EASC/ home.html. Consulta del 17-8-1998.

Ministerio de Cultura y Educación (MCyE) (1998b), El Equipo Docente. Revista Zona Educativa No. 22. año 3. MCE. Buenos Aires. 